\title{
Investigation of Electrocatalytic Properties of Pt/Mo - Expanded Graphite Composite Derived from Graphite Intercalation Compound
}

\author{
J. URBANiAK AND J.M. SkOWROŃSKI* \\ Institute of Chemistry and Technical Electrochemistry, Poznań University of Technology \\ Pl. M. Skłodowskiej-Curie 5, 60-965 Poznań, Poland
}

\begin{abstract}
In the present work, electrocatalytic properties of $\mathrm{Pt}-\mathrm{EG}$ and $\mathrm{Pt} / \mathrm{Mo}-\mathrm{EG}$ composite electrodes are studied. These composites were prepared by a three-step synthesis. First, stage- $1 \mathrm{HClO}_{4}-\mathrm{GIC}$ was synthesized using the chronopotentiometric method. Then, $\mathrm{HClO}_{4}-\mathrm{GIC}$ was heat treated to obtain expanded graphite. Finally, expanded graphite was coated with platinum catalyst from a water-alcohol solution of $\mathrm{H}_{2} \mathrm{PtCl}{ }_{6}$. $\mathrm{MoCl}_{5}-\mathrm{GIC}$ synthesized in parallel was subjected to thermal exfoliation to get Mo-EG composite onto which platinum catalyst was dispersed. The X-ray diffraction and energy dispersive X-ray analyses coupled with scanning electron microscopy were applied for characterizing the obtained GICs and EG-based composites, whereas cyclic voltammetry was used to study electrocatalytic properties of $\mathrm{Pt} / \mathrm{EG}$ and $\mathrm{Pt} / \mathrm{Mo}-\mathrm{EG}$ composite electrodes in sulfuric acid and sulfuric acid admixed with methanol.
\end{abstract}

PACS numbers: 82.47.Gh, 82.80.Fk

\section{Introduction}

Nowadays, special interest is paid to supported catalysts. Due to the fine dispersion of metallic particles a much larger number of catalytic sites is accessible for reagents than in a corresponding bulk metal. Among supports, carbons such as activated carbon, carbon black, graphite and graphitized material are used [1]. Recently, the use of expanded graphite as a catalyst support was also reported $[2,3]$.

The main requirements for carbon supports used for electrochemical applications are: a large surface area, high porosity and good electric conductivity. To achieve such features natural graphite is modified via the preparation of graphite intercalation compound (GIC) and its subsequent exfoliation resulting in expanded graphite. Graphite intercalation compounds are formed after insertion of chemical species into interlayer spacings of graphite [4]. The guest species are called intercalates and the product of the reaction is called graphite intercalation compound. Expanded graphite (EG) is commonly produced via thermal treatment of GIC. During the process both the huge expansion of expanded graphite along the $c$-axis and increase in specific surface area are observed [5-8].

Platinum catalysts deposited on carbon supports are widely used as electrode materials in proton exchange

* corresponding author; e-mail: jan.skowronski@put.poznan.pl membrane fuel cells (PEMFC) [9]. It is well known that platinum catalyst is easily poisoned by carbon monoxide. Therefore, various Pt-based binary and ternary catalysts such as $\mathrm{Pt}-\mathrm{Ru}, \mathrm{Pt}-\mathrm{Sn}, \mathrm{Pt}-\mathrm{Mo}, \mathrm{Pt}-\mathrm{Ru}-\mathrm{Mo}$ have been intensively investigated to eliminate the poisoning effect [9-11]. Moreover, all the time considerable efforts are taken to develop novel binary and ternary catalysts with enhanced catalytic activities for methanol oxidation $[12,13]$.

The aim of this work is to present preliminary results concerning the electrocatalytic properties of $\mathrm{Pt}-\mathrm{EG}$ and $\mathrm{Pt} / \mathrm{Mo}-\mathrm{EG}$ composite electrodes in which expanded graphite and expanded graphite intercalation compound with Mo species are used as supports for platinum particles.

\section{Experimental}

In this work $\mathrm{Pt}-\mathrm{EG}$ and $\mathrm{Pt} / \mathrm{Mo}-\mathrm{EG}$ composites were prepared by a three-step synthesis. First, GIC with perchloric acid $\left(\mathrm{HClO}_{4}-\mathrm{GIC}\right)$ and GIC with $\mathrm{MoCl}_{5}\left(\mathrm{MoCl}_{5}{ }^{-}\right.$ GIC) were synthesized. $\mathrm{HClO}_{4}-$ GIC was synthesized by anodic oxidation of natural graphite flakes (99.98 wt\% carbon content from Graphitwerk Kropfmühl AG) in 70\% $\mathrm{HClO}_{4}$ using the chronopotentiometric method [14]. The platinum disk served as the working electrode and a platinum plate was employed as the counter electrode. Intercalation was terminated after passing the anodic charge of $335 \mathrm{As} / \mathrm{g}$ which corresponds to the preparation of stage- $1 \mathrm{HClO}_{4}$-GIC. After synthesis, the product of intercalation was washed with distilled water and acetone 
and dried in air. $\mathrm{MoCl}_{5}-\mathrm{GIC}$ was prepared by intercalation of natural graphite flakes (99.98 wt\% carbon content from Graphitwerk Kropfmühl AG) with molybdenum chloride by the two-bulb method. Before the glass reactor was filled, $\mathrm{MoCl}_{5}$ was exposed to air with $55 \%$ humidity at $25^{\circ} \mathrm{C}$ for $10 \mathrm{~min}$ according to the procedure described by Mittal and Inagaki [15]. Next, the glass reactor was filled with the mixture of air-exposed $\mathrm{MoCl}_{5}$ and graphite flakes and sealed. The process of intercalation was performed at $300{ }^{\circ} \mathrm{C}$ for 7 days. After intercalation was terminated, the reactor was cooled down and opened. The product of intercalation was washed with distilled water and acetone and dried in air.

To obtain exfoliated graphite, GICs put in open ceramic boats were placed in quartz reactor and then heat treated at $700{ }^{\circ} \mathrm{C}$ in $\mathrm{N}_{2}$ atmosphere for $5 \mathrm{~h}$. For characterizing the structure of $\mathrm{MoCl}_{5}-\mathrm{GIC}, \mathrm{Pt}-\mathrm{EG}$ and $\mathrm{Pt} / \mathrm{Mo}-$ EG the X-ray diffraction (XRD) measurements were performed using $\mathrm{Cu} K_{\alpha}$ radiation. In the $3 \mathrm{rd}$ step of the synthesis, the composites with platinum were prepared by the ethylene glycol reduction method [16]. First, samples were suspended in ethylene glycol and dispersed ultrasonically for $2 \mathrm{~h}$, afterwards a solution of chloroplatinic acid containing $10 \mathrm{mg}$ of $\mathrm{Pt}$ was added to the slurry and the flask was placed in an oil bath at $130^{\circ} \mathrm{C}$ for $3 \mathrm{~h}$.

Electrochemical behavior of $\mathrm{Pt}-\mathrm{EG}$ and $\mathrm{Pt} / \mathrm{Mo}-\mathrm{EG}$ electrodes was investigated in a three-electrode system with a potentiostat-galvanostat PGSTAT30 Autolab (EcoChemie B.V.). The $\mathrm{Hg} / \mathrm{Hg}_{2} \mathrm{SO}_{4} / 1 \mathrm{M} \mathrm{H}_{2} \mathrm{SO}_{4}$ system ( $E=0.67 \mathrm{~V}$ vs. standard hydrogen electrode) was employed as the reference electrode. All potentials throughout the paper are referred to this electrode. Gold plate was used as a counter electrode. The electrolyte was $0.5 \mathrm{M} \mathrm{H}_{2} \mathrm{SO}_{4}$ solution with or without $0.5 \mathrm{M}$ methanol. The cyclic voltammetric $(\mathrm{CV})$ measurements were carried out in three potential ranges: $-0.67 \mathrm{~V} \leftrightarrow 0.23 \mathrm{~V}$, $-0.67 \mathrm{~V} \leftrightarrow 0.38 \mathrm{~V}$ and $-0.67 \mathrm{~V} \leftrightarrow 0.98 \mathrm{~V}$. Starting from the rest potential of electrode, the potential was changed in the negative direction (cathodic polarization) with a scan rate $10 \mathrm{mV} / \mathrm{s}$. After the reversal of polarization direction, the potential was changed in the positive direction (anodic polarization). All electrochemical measurements were carried out at a room temperature. The current density for $\mathrm{Pt}-\mathrm{EG}$ and $\mathrm{Pt} / \mathrm{Mo}-\mathrm{EG}$ composites investigated in electrolyte admixed with methanol were calculated as the ratio of current to Pt mass. Platinum mass in Pt-EG and $\mathrm{Pt} / \mathrm{Mo}-\mathrm{EG}$ composites was determined from the EDX semiquantitative analysis. The energy dispersive X-ray measurements were carried out on a PGT model Prism 2000 coupled with a scanning electron microscope Tescan model Vega 5135MM.

\section{Results and discussion}

$\mathrm{HClO}_{4}-\mathrm{GIC}$ can be prepared by both chemical and electrochemical methods. While stage- $2 \mathrm{HClO}_{4}-\mathrm{GIC}$ can be obtained by chemical method, the electrochemical method is more effective allowing to prepare stage-1
$\mathrm{HClO}_{4}-$ GIC. During the process of exfoliation of $\mathrm{HClO}_{4}-$ GIC, due to the process of decomposition, the intercalate $\left(\mathrm{ClO}_{4}^{-} / \mathrm{HClO}_{4}\right)$ is entirely released from the graphite lattice.

Figure 1 presents X-ray diffraction pattern recorded for Pt-EG composite obtained after thermal exfoliation of $\mathrm{HClO}_{4}$ - GIC followed by platinum deposition onto the EG surface in ethylene glycol solution. The diffraction peaks related to the graphite phase together with $h k l$ reflections characteristic of the $\mathrm{Pt}$ phase are observed. Based on the diffractogram it may be stated that platinum exists as a face-centered cubic structure. Energy dispersive X-ray (EDX) semiquantitative analysis indicated that average $\mathrm{Pt}$ content in $\mathrm{Pt}-\mathrm{EG}$ composite was equal to $c a .10 \mathrm{wt} \%$.

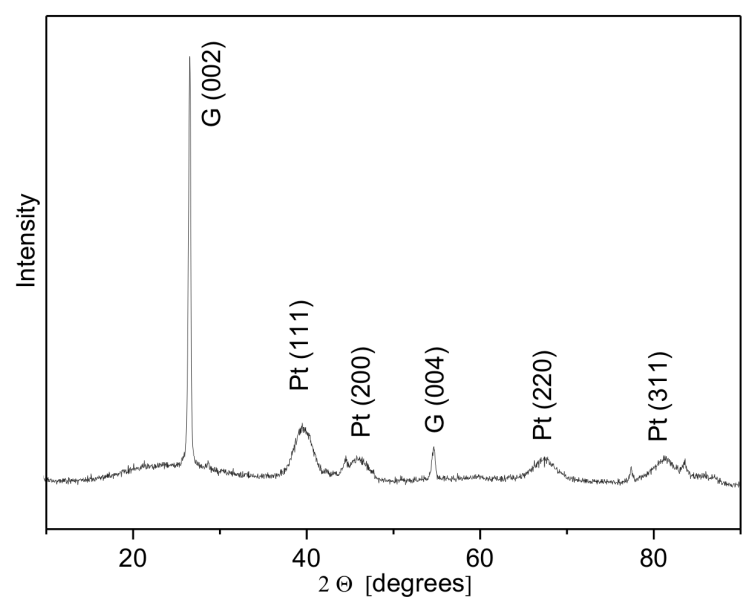

Fig. 1. X-ray pattern of Pt-expanded graphite composite.

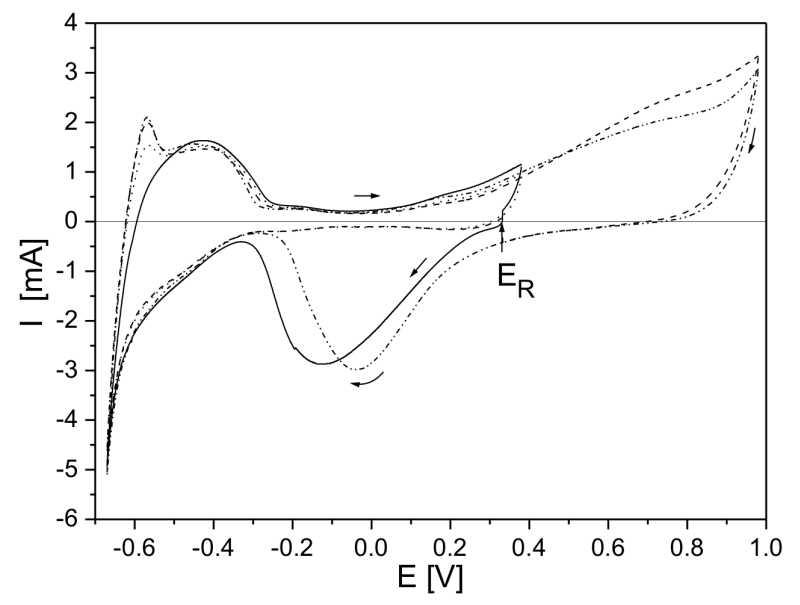

Fig. 2. CV curves recorded for Pt-EG composite in $0.5 \mathrm{M} \mathrm{H}_{2} \mathrm{SO}_{4}$. Cycles $1(-)$ and $3(\cdots)$ were carried out in the potential range $-0.67 \mathrm{~V} \leftrightarrow 0.38 \mathrm{~V}$, cycles $6(--)$ and $8(-\cdot-\cdot \cdot)$ in the potentialrange $-0.67 \mathrm{~V} \leftrightarrow 0.98 \mathrm{~V}$.

Figure 2 presents CV curves recorded for Pt/EG electrode in $0.5 \mathrm{M}$ sulfuric acid solution. Starting from the rest potential of the electrode $(0.33 \mathrm{~V})$ towards negative 
direction, a huge irreversible cathodic peak with the current maximum at $-0.13 \mathrm{~V}$ is recorded. After five cycles in the potential range of $-0.67 \mathrm{~V} \leftrightarrow 0.38 \mathrm{~V}$, the upper limit of the potential sweep was raised to $0.98 \mathrm{~V}$ and further 5 cycles were recorded. Comparing the first cycle with $\mathrm{CV}$ curves obtained in a wider potential range, one can infer that the peak noted in the first cycle is associated with the reduction of platinum oxide. This conclusion corroborates with a well-known fact that the surface of $\mathrm{Pt}$ nanoparticles is covered with the layer of $\mathrm{Pt}$ oxide. In the potential range from $-0.30 \mathrm{~V}$ to $-0.67 \mathrm{~V}$, the process of the formation of adsorbed hydrogen atoms $H_{\text {ads }}$ at the platinum surface is recorded. After the reversal of polarization the process of hydrogen desorption is revealed on CV curve as the anodic peak at $-0.58 \mathrm{~V}$. As can be seen, in the successive cycles, the hydrogen desorption currents related to weakly bound hydrogen (current peak at $-0.59 \mathrm{~V}$ ) are higher and better defined than in the first cycle [17]. The anodic currents observed in the region of desorption of medium and strong bound hydrogen (currents in the range $-0.55 \leftrightarrow-0.33 \mathrm{~V}$ ) show a slight increase, however, no peaks are formed [17].

It is generally accepted that the process of methanol oxidation may be described by simplified mechanism [18]:

$$
\begin{aligned}
& \mathrm{CH}_{3} \mathrm{OH} \rightarrow\left(\mathrm{CH}_{3} \mathrm{OH}\right)_{\mathrm{ad}}, \\
& \left(\mathrm{CH}_{3} \mathrm{OH}\right)_{\mathrm{ad}} \rightarrow(\mathrm{CO})_{\mathrm{ad}}+4 \mathrm{H}^{+}+4 \mathrm{e}^{-}, \\
& (\mathrm{CO})_{\mathrm{ad}}+\mathrm{H}_{2} \mathrm{O} \rightarrow \mathrm{CO}_{2}+2 \mathrm{H}^{+}+2 \mathrm{e}^{-} .
\end{aligned}
$$

During the electrochemical oxidation of methanol in acid solution the process begins with the coverage of the electrode surface with the methanol adsorbate.

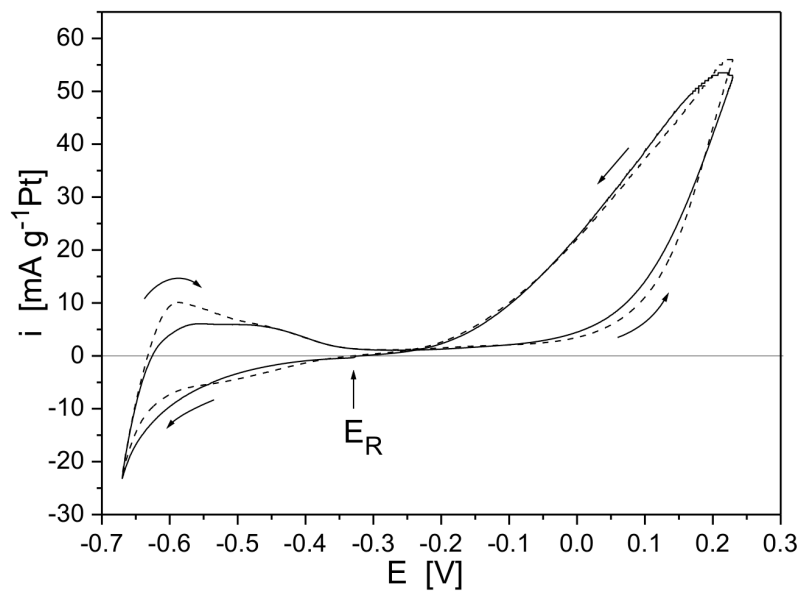

Fig. 3. CV curves recorded for Pt-EG composite in $0.5 \mathrm{M} \mathrm{H}_{2} \mathrm{SO}_{4}$ with $0.5 \mathrm{M}$ of methanol. Cycle 1 (-), cycle 3 (---).

In Fig. 3, the behavior of Pt-EG composite electrode in the mixture of methanol and sulfuric acid is presented. An addition of methanol to sulfuric acid shifts a rest potential about $0.65 \mathrm{~V}$ towards negative potentials. This shift is probably due to the methanol adsorption on the platinum sites. After the reversal of polarization from the

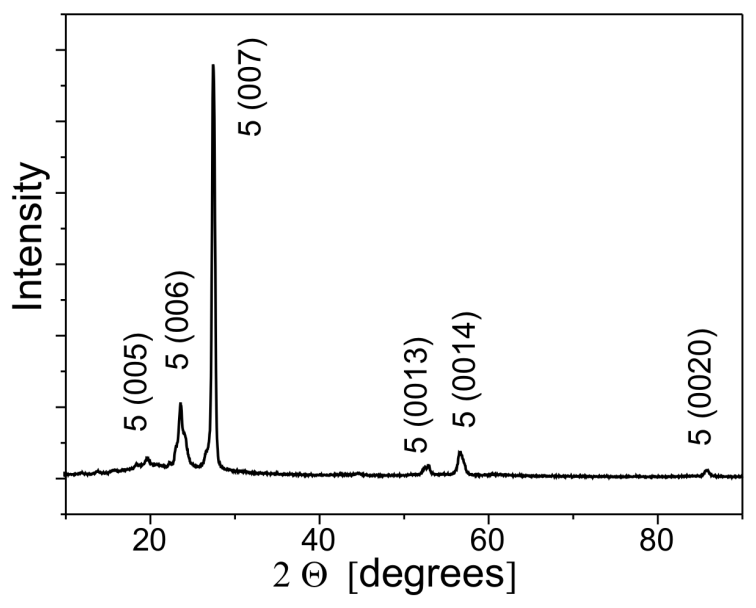

Fig. 4. X-ray pattern of stage- $5 \mathrm{MoCl}_{5}-$ GIC.

cathodic to anodic direction (at $-0.67 \mathrm{~V}$ ), an increase of anodic current associated with the process of methanol oxidation is observed at about $0.1 \mathrm{~V}$. This increase is observed until the potential of reversion is reached $(0.23 \mathrm{~V})$. After the reversal of polarization, during the potential scanning towards negative direction, a gradual decrease of anodic current takes place until the potential of $c a$. $-0.3 \mathrm{~V}$ is reached.

Figure 4 presents XRD pattern for GIC obtained from the mixture of natural graphite and $\mathrm{MoCl}_{5}$. From this pattern it was calculated that the product of synthesis was built up of domains of stage- $5 \mathrm{MoCl}_{5}-\mathrm{GIC}\left(I_{\mathrm{c}}=\right.$ $2.263 \mathrm{~nm}, d_{i}=0.923 \mathrm{~nm}$ ).

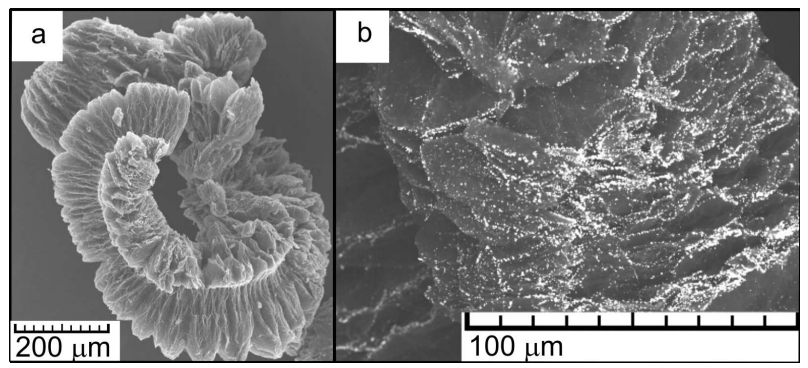

Fig. 5. SEM micrograph obtained for Mo-EG composite.

When exfoliation of GIC with metal chloride takes place, some part of intercalate could be preserved in the graphite lattice. If so, the obtained product is recognized as expanded graphite intercalation compound. As revealed by the scanning electron microscope analysis, expanded $\mathrm{MoCl}_{5}$-GIC exhibits a worm-like structure (Fig. 5a). Small bright spots related to the presence of decomposed intercalate particles are observed on the graphite surface (Fig. 5b) which means that the product of exfoliation should be recognized as expanded graphite composite (Mo-EG). As can be seen in Fig. 5, higher amount of these spots is located near the edges of ex- 


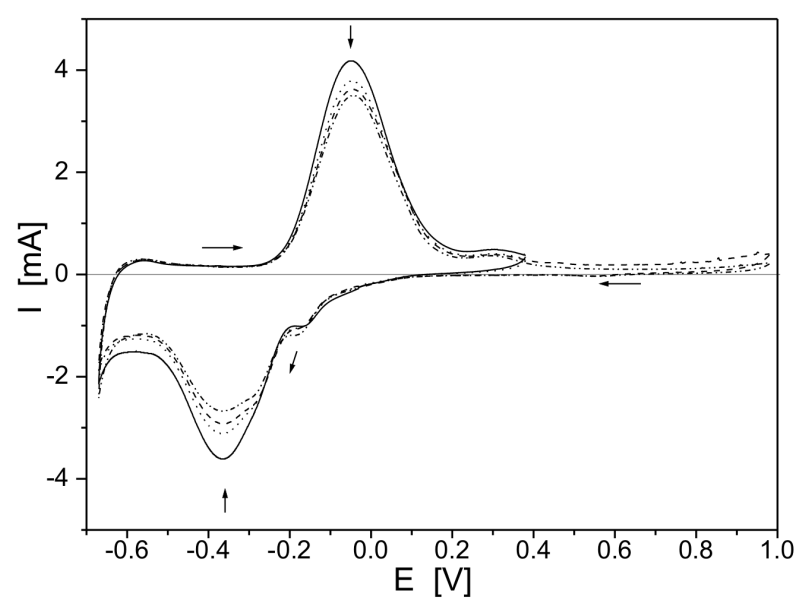

Fig. 6. CV curves recorded for Mo-EG composite in $0.5 \mathrm{M} \mathrm{H}_{2} \mathrm{SO}_{4}$. Cycles $3(-)$ and $5(\ldots)$ were carried out in the potential range $-0.67 \mathrm{~V} \leftrightarrow 0.38 \mathrm{~V}$, cycles $6(---)$ and $8(-\cdot \cdot-\cdot \cdot)$ in the potential range $-0.67 \mathrm{~V} \leftrightarrow 0.98 \mathrm{~V}$.

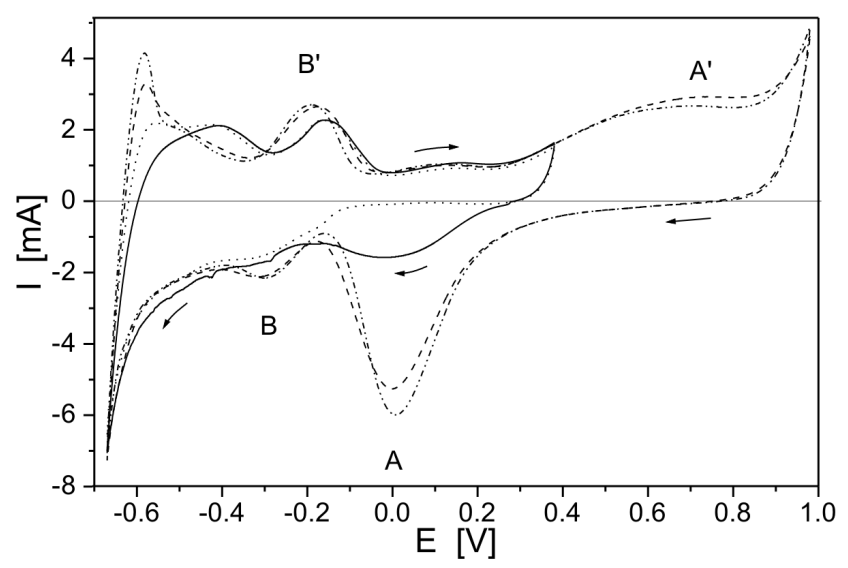

Fig. 7. CV curves recorded for $\mathrm{Pt} / \mathrm{Mo}-\mathrm{EG}$ composite in $0.5 \mathrm{M} \mathrm{H}_{2} \mathrm{SO}_{4}$. Cycles $1(-)$ and $3(\ldots)$ were carried out in the potential range $-0.67 \mathrm{~V} \leftrightarrow 0.38 \mathrm{~V}$, cycles 6 $(--)$ and $8(-\cdots-\cdots)$ in the potential range $-0.67 \mathrm{~V} \leftrightarrow$ $0.98 \mathrm{~V}$.

panded particles. The composition of Mo-EG composite was analyzed by the EDX analysis. EDX semiquantitative analysis indicated that the atomic ratios of $\mathrm{Mo}: \mathrm{O}$ and $\mathrm{Mo}: \mathrm{Cl}$ are $1: 1.15$ and $1: 0.22$, respectively.

In Fig. 6 voltamperometric curves recorded for $\mathrm{Mo}^{-}$ EG electrode in sulfuric acid solution are shown. On cycling, a small cathodic peak at about $-0.17 \mathrm{~V}$ followed by the main cathodic peak with the current maximum at $-0.36 \mathrm{~V}$ are observed. After the reversal of polarization, anodic current peak with the current maximum at $-0.05 \mathrm{~V}$ is recorded. These redox peaks may be attributed to a $\mathrm{Mo}(\mathrm{VI}) / \mathrm{Mo}(\mathrm{IV})$ transformation of $\mathrm{Mo}$ species $[19,20]$. The height of these redox peaks decreases on increasing the time of cycling. Such a behavior may indicate that Mo species present on the surface of expanded graphite dissolve into the electrolyte [21].
Figure 7 presents CV curves recorded for Pt/Mo-EG electrode cycled in sulfuric acid. After starting from the rest potential of electrode $\left(E_{\mathrm{R}}=0.28 \mathrm{~V}\right)$ towards negative direction a cathodic peak associated with the reduction of platinum oxide is recorded. When cycling is performed in the potential range $-0.67 \mathrm{~V} \leftrightarrow$ $0.38 \mathrm{~V}$, the hydrogen region and the peak corresponding to the reduction of molybdenum compounds are practically not separated in the cathodic run of a voltammogram. In contradistinction to cyclic voltammogram for Pt-EG (Fig. 2), in Fig. 7 except effects related to the hydrogen adsorption-desorption and the process of platinum oxidation and its reduction $\left(A^{\prime} / A\right)$, a new pair of redox peaks (marked $B / B^{\prime}$ ) is noted. Similar to $\mathrm{CV}$ curves recorded for Mo-EG (Fig. 6) the pair of redox peaks marked $B / B^{\prime}$ in Fig. 7 may be related to the reduction/oxidation of some molybdenum-containing species. The presence of these redox pair means that during the process of platinum deposition, molybdenum species are not removed from the surface of expanded graphite. It should be noted that the maxima of these peaks are about $0.15 \mathrm{~V}$ shifted towards more negative potentials. Besides, during the measurement in the potential range of $-0.67 \mathrm{~V} \leftrightarrow 0.38 \mathrm{~V}$ only a slight current decrease is observed. When the measurement is performed in a wider potential range, the peak current for both voltammetric peaks $B / B^{\prime}$ increases and no noticeable decrease of these currents is observed on cycling. Such a behavior is similar to the results of studies carried out for polycrystalline PtMo alloy electrodes [22, 23]. These results showed that contrary to Mo electrodes, $\mathrm{Pt}_{0.75} \mathrm{Mo}_{0.25}$ and $\mathrm{Pt}_{0.70} \mathrm{Mo}_{0.30}$ alloys are stable in $0.5 \mathrm{M} \mathrm{H}_{2} \mathrm{SO}_{4}$ and do not exhibit any loss of Mo upon cycling. Based on this, the improvement of stability of investigated $\mathrm{Pt} / \mathrm{Mo}-\mathrm{EG}$ electrode in conjunction with the shift of the maxima of $B / B^{\prime}$ peaks suggests the formation of PtMo phase during the process of platinum deposition in ethylene glycol.

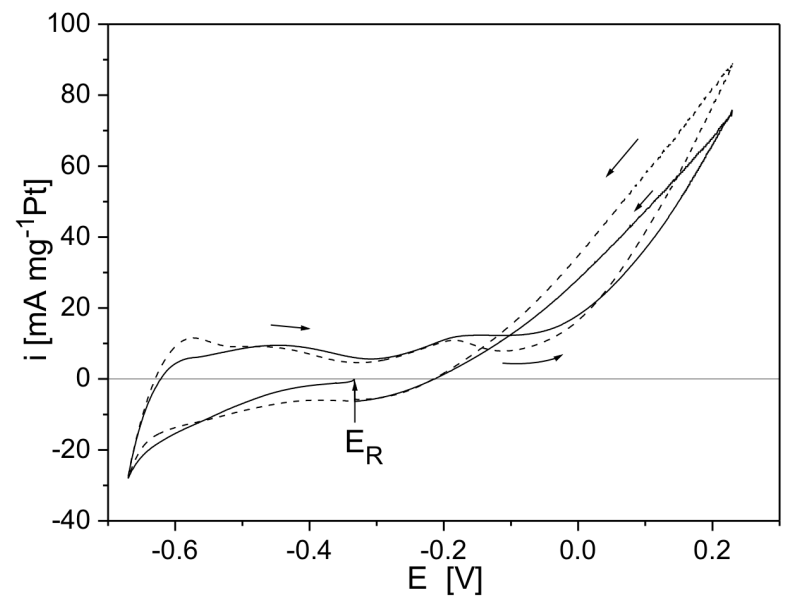

Fig. 8. CV curves recorded for Pt/Mo-EG composite in $0.5 \mathrm{M} \mathrm{H}_{2} \mathrm{SO}_{4}$ with $0.5 \mathrm{M}$ of methanol. Cycle $1(-)$, cycle 3 (---). 
In Fig. 8 the behavior of $\mathrm{Pt} / \mathrm{Mo}-\mathrm{EG}$ composite electrode in the mixture of methanol and sulphuric acid is shown. Similar to Pt-EG composite, also in this case an addition of methanol to sulphuric acid shifts the rest potential of the electrode to the value about $-0.34 \mathrm{~V}$ (the value in $\mathrm{H}_{2} \mathrm{SO}_{4}$ solution free of methanol amounts $0.28 \mathrm{~V}$, Fig. 7). For Pt/Mo-expanded graphite composite in sulphuric acid admixed with methanol, the process of methanol oxidation is observed. This process begins at about $0.05 \mathrm{~V}$ more negative potential as compared with Pt-EG composite. Furthermore, the increase in catalytic activity of $\mathrm{Pt} / \mathrm{Mo}-\mathrm{EG}$ composite towards methanol oxidation is observed. The current density for Pt/Mo-EG composite at the potential of reversion, calculated as the ratio of current to $\mathrm{Pt}$ mass is about $25 \%$ higher as compared with the value noted for Pt-EG composite (Fig. 3).

\section{Conclusions}

Electrochemical behavior of expanded graphite supported $\mathrm{Pt}$ and $\mathrm{Pt} / \mathrm{Mo}$ electrocatalysts prepared by a three-step synthesis are presented. Pt/Mo-EG composite is shown as promising electrode material for methanol electrooxidation. Our results showed that contrary to Mo-EG electrode, $\mathrm{Pt} / \mathrm{Mo}-\mathrm{EG}$ electrode is stable in $0.5 \mathrm{M}$ $\mathrm{H}_{2} \mathrm{SO}_{4}$ and does not exhibit any loss of Mo upon cycling. Moreover, electrochemical measurements proved that the process of methanol oxidation is improved when $\mathrm{MoCl}_{5}$ GIC is used as a precursor of carbon support instead $\mathrm{HClO}_{4}-\mathrm{GIC}$. The specific mass activity of $\mathrm{Pt} / \mathrm{Mo}-\mathrm{EG}$ composite is ca. $25 \%$ higher as compared with that measured for Pt-EG composite electrode.

\section{Acknowledgments}

Financial support for this work from the grant No. BW $31-181 / 09$ is gratefully acknowledged.

\section{References}

[1] E. Auer, A. Freund, J. Pietsch, T. Tacke, Appl. Catal. A 173, 259 (1998).

[2] B.N. Kuznetsov, N.V. Chesnokov, N.M. Mikova, V.I. Zaikovskii, V.A. Drozdov, M.V. Savos'kin, A.M. Yaroshenko, S.B. Lyubchik, React. Kinet. Catal. Lett. 80, 345 (2003).
[3] A. Bhattacharya, A. Hazra, S. Chatterjee, P. Sen, S. Laha, I. Basumallick, J. Power Sources 136, 208 (2004).

[4] J.M. Skowroński, in: Handbook of Organic Conductive Molecules and Polymers, Ed. H.S. Nalwa, Wiley, Chichester 1997, p. 621.

[5] D.D.L. Chung, J. Mater. Sci. 22, 4190 (1987).

[6] J.M. Skowroński, J. Mater. Sci. 23, 2243 (1988).

[7] J.M. Skowroński, P. Krawczyk, J. Solid State Electrochem. 8, 442 (2004).

[8] J.M. Skowroński, P. Krawczyk, T. Rozmanowski, J. Urbaniak, Energy Convers. Manage. 49, 2440 (2008).

[9] E. Antolini, Appl. Catal. B 74, 324 (2007).

[10] E. Antolini, Appl. Catal. B 74, 337 (2007).

[11] S. Mukerjee, R.C. Urian, Electrochim. Acta 47, 3219 (2002).

[12] J.-H. Choi, K.-W. Park, I.-S. Park, W.-H. Nam, Y.-E. Sung, Electrochim. Acta 50, 787 (2004).

[13] V.V. Kuznetsov, A.A. Kalinkina, T.V. Pschenichkina, Russian J. Electrochem. 43, 776 (2007).

[14] J.O. Besenhard, P. Minderer, M. Bindl, Synth. Met. 34, 133 (1989).

[15] J. Mittal, M. Inagaki, Solid State Ionics 121, 183 (1999).

[16] Z. Zhou, S. Wang, W. Zhou, G. Wang, L. Jiang, W. Li, S. Song, J. Liu, G. Sun, Q. Xin, Chem. Commun., 394 (2003).

[17] K. Kinoshita, J.T. Zuindquist, O. Stonehart, J. Electroanal. Chem. 48, 157 (1973).

[18] E. Antolini, T. Lopes, E.R. Gonzales, J. Alloys Comp. 461, 253 (2007).

[19] M. Pourbaix, Atlas of Electrochemical Equilibria in Aqueous Solutions, Pergamon Press, Brussels 1966.

[20] A.O. Neto, J. Perez, W.T. Napporn, E.A. Ticianelli, E.R. Gonzales, J. Braz. Chem. Soc. 11, 39 (2000).

[21] N.P. Lebedeva, G.J.M. Janssen, Electrochim. Acta 51, 29 (2005).

[22] B.N. Grgur, G. Zhuang, N.M. Markovic, P.N. Ross Jr., J. Phys. Chem. B 101, 3910 (1997).

[23] B.N. Grgur, N.M. Markovic, P.N. Ross, Jr., J. Phys. Chem. B 102, 2494 (1998). 